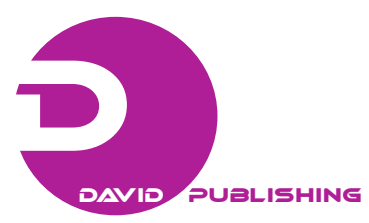

\title{
The Effect of Molar Liquid Water-Gas Ratio on Methane Hydrate Formation
}

\author{
Wei Ke and Thor M. Svartaas \\ Department of Petroleum Engineering, Faculty of Science and Technology, University of Stavanger, Stavanger4036, Norway
}

Received: April 30, 2013 / Accepted: June 01, 2013 / Published: August 25, 2013

\begin{abstract}
Experimental results and analysis among different hydrate research groups are very often not transplantable, partly due to the intrinsic stochastic nature of hydrate formation, partly due to different experimental conditions, gas compositions and analyzing techniques used or applied. In the present work the effect of the molar liquid water-gas ratio $\left(\gamma_{m}\right)$ on both nucleation and growth of methane hydrate has been examined. Structure I methane hydrates were formed under isochoric conditions in stirred cell during constant cooling, and the point of spontaneous nucleation (PSN) was recorded. The results show that change of $\gamma_{m}$ gave no significant effect on average induction time, average nucleation rate or average sub-cooling at PSN. Nevertheless, nucleation behaved more stochastic when the volume fraction of water and $\gamma_{m}$ increased. Moderate $\gamma_{m}$ values that were closer to the theoretical hydration number (5.9 to 6 at the experimental conditions) could achieve larger total gas consumption and higher hydrate formation rate. "Imbalanced" $\gamma_{m}$ values (either highly water-excess or highly gas-excess) may however lead to smoother behavior of crystal growth.
\end{abstract}

Key words: Methane hydrate, liquid water-gas mass ratio, nucleation, growth.

\section{Nomenclature}

b: $\quad$ Dimensionless thermodynamic parameter

$d T / d t: \quad$ Cooling rate $\left({ }^{\circ} \mathrm{C} / \mathrm{h}\right)$

$J: \quad$ Nucleation rate $\left(\mathrm{m}^{-3} \mathrm{~s}^{-1}\right)$

$K_{j}: \quad$ Kinetic factor $\left(\mathrm{m}^{-3} \mathrm{~s}^{-1}\right)$

$t_{i}: \quad$ Induction time (min)

$T_{e}: \quad$ Equilibrium temperature $\left({ }^{\circ} \mathrm{C}\right)$

$\Delta T: \quad$ Subcooling $\left({ }^{\circ} \mathrm{C}\right)$

$\gamma_{\mathrm{m}}: \quad$ Molar liquid water-gas ratio

$n_{w}: \quad$ Amount of water (mol)

$n_{g}: \quad$ Amount of gas (mol)

\section{Introduction}

Clathrate compounds of natural gas with liquid water or ice have drawn continuous interest in both academia and industry for centuries. Research of different levels and varying scales has been carried out and presented with gradually increasing focus on the kinetics of hydrate formation instead of thermodynamic properties [1-2]. Seeing hydrate formation as a continuous crystallization process

Corresponding author: Wei Ke, research field: natural gas hydrates. E-mail: wei.ke@uis.no. which consists of nucleation and growth, there have been studies on nucleation phenomena and the induction period [3-4]. Based on lab scale research, mass and heat transfer models during crystal growth have been established [5-7].

With theoretical assistance from phase-field theory [8] some researchers argue that the chemical diffusion of gas into liquid phase is the rate determining process during hydrate formation and growth. A large quantity of modeling work has been carried out and published to help gain further insights of hydrate formation kinetics [9-10]. Previous research on hydrate nucleation has in general reached the same conclusion that compared to hydrate growth, nucleation is a stochastic process. As has been pointed out in the literature [11], "Stochastic Nucleation" has very rich meanings. Not only the number of nuclei formed in a saturated solution within a certain period of time is stochastic, but the time point for the first nuclei to appear is unpredictable. Also, the clustering of nuclei that 
surpass a critical size to start spontaneous growth is a random process. Hydrate growth, the stage after nucleation with auto-catalytic growing nuclei in the bulk phase, has more regular and predictable behavior.

Considering a simplest and most representative scenario, a gas hydrate formation as a transition process from two phase (gas and water) to three phase (gas, water, and hydrate) in a closed system with fixed total mass, it is natural to wonder: Could the relative molar ratios between co-existing phases present in the reaction system have an effect on the nucleation and growth processes? Studies [12] have shown that, for instance, the already formed hydrates may present an "inhibiting effect" on the ongoing formation process, by preventing a sufficient contact between gas phase and the free water phase, even when continuous stirring is applied in the system. In a closed system such an effect from the solid hydrate phase could slow down or even stop hydrate formation before a thermodynamic equilibrium pressure could be reached. Concerning this observation, it could be reasonable to pose the following question: Could a varying molar ratio of initial free water and gas in a stirred, constant volume reactor have an effect on both the hydrate nucleation and growth processes?

In the present work, the effect of varying initial liquid water-gas mass ratio on structure-I methane hydrate formation has been examined in a closed, isochoric hydrate forming system.

\section{Experimental Methods}

A lab-scale isochoric high pressure titanium cell with an inner volume of $145 \mathrm{~mL}$ was used to study the effect of the molar liquid water-gas ratio $\left(\gamma_{m}=n_{w} / n_{g}\right)$ on methane hydrate nucleation and growth. Methane gas of scientific grade 5.5 (purity 99.9995\%) was used as hydrate forming gas together with distilled water (DIW). Real-time temperature and pressure was monitored by sensors, exposed directly to the inner part of the cell where the hydrate formation process took place.

$10 \mathrm{~mL}, 20 \mathrm{~mL}, 50 \mathrm{~mL}$, and $100 \mathrm{~mL}$ initial volume of DIW were chosen for separate methane hydrate nucleation and growth experiments. The volume of methane gas was then $135 \mathrm{~mL}, 125 \mathrm{~mL}, 90 \mathrm{~mL}$ and 45 $\mathrm{mL}$ correspondingly in the isochoric cell. At initial PT condition of 90.5 bar and $14.1{ }^{\circ} \mathrm{C}$ these four sets represent initial molar liquid water-methane gas ratios of $0.90,1.94,6.41$ and 27.71 , respectively. Considering a stoichiometric molar ratio of 5.75 for methane hydrate, the $10 \mathrm{~mL}, 20 \mathrm{~mL}$ DIW experiments were gas-excess, $50 \mathrm{~mL}$ DIW experiment was close to theoretical value while $100 \mathrm{~mL}$ DIW experiment was water-excess. A total number of 10 experiments were conducted at each $\gamma_{\mathrm{m}}$ ratio.

A fixed stirring rate of $660 \mathrm{rpm}$ and a fixed cooling rate of $6{ }^{\circ} \mathrm{C} / \mathrm{h}$ were applied in all hydrate nucleation and growth experiments conducted. More details of the effects of varying stirring rates and cooling rates on methane hydrate formation is given by $\mathrm{Ke}$, et al. [13]. All experiments were started at fixed initial pressure of around 90.5 bar and a fixed initial temperature of around $14.1{ }^{\circ} \mathrm{C}$. Methane hydrate equilibrium curve was obtained from Ref. [14]. A more detailed description of experimental setup and experimental procedure is given by $\mathrm{Ke}$, et al. [15].

\section{Results}

\subsection{Hydrate Nucleation}

Measured effects of molar liquid water-gas ratios on induction time and subcooling at point of spontaneous methane hydrate nucleation (PSN) are given in Table 1. The table shows the average subcooling, $\Delta T$, and average induction time according to Eq. (1) $\pm \mathrm{SD}$. The average was based on 10 experiments at each $\gamma_{m}$. During all experiments other conditions such as stirring rate, cooling rate, initial $\mathrm{P}$ and $\mathrm{T}$ conditions at start of experiments were kept constant $\left(660 \mathrm{rpm}, 6{ }^{\circ} \mathrm{C} / \mathrm{h}, 90.5\right.$ bar, $14.1{ }^{\circ} \mathrm{C}$, respectively). 
Table 1 Table showing results of nucleation experiments with varying molar liquid water-gas ratio $\left(\gamma_{\mathrm{m}}\right)$ in the cell.

\begin{tabular}{ccc}
\hline Initial Molar liquid water-gas ratio $\left(\gamma_{m}\right)$ & Induction time $(\mathrm{min})$ & Subcooling $\left({ }^{\circ} \mathrm{C}\right)$ \\
\hline 0.90 & $39.5 \pm 4.3$ & $3.8 \pm 0.4$ \\
1.94 & $34.8 \pm 4.1$ & $3.4 \pm 0.4$ \\
6.41 & $35.0 \pm 8.1$ & $3.4 \pm 0.8$ \\
27.71 & $45.0 \pm 14.2$ & $4.4 \pm 1.4$ \\
\hline
\end{tabular}

At constant cooling rate, $d T / d t(6 \mathrm{oC} / \mathrm{h})$, induction time ti is linearly related to the degree of subcooling, $\Delta T$, as given by Eq. (1):

$$
t_{i}=\frac{\Delta T}{d T / d t}
$$

Fig. 1 shows average degree of subcooling \pm SD (standard deviation) at the different molar liquid water-gas ratios $(\gamma m)$ examined.

There are different methods to obtain and describe hydrate nucleation rate. A simple method like real-time nuclei counting with help of a high-resolution camera [16] is not applicable in the non- transparent cell used in this work. Thus the experimentally observed first sign of gas consumption by incipient hydrate formation has been used for detection of PSN (point of spontaneous nucleation). The slight temperature increase at hydrate onset point due to exothermic reaction of hydrate formation was also used for confirmation of PSN. As described in other paper by Ke et al. [15], the model by Kashchiev et al. [17] was used for calculation of time-dependent average nucleation rate, $\mathrm{J}(\mathrm{m}-3 \mathrm{~s}-1)$, in the present work. According to Kaschiev et al. the nucleation rate in continuously cooled systems can be expressed by:

$$
J=K_{J} \exp \left[-b /\left(1-\Delta T / T_{e}\right)\left(\Delta T / T_{e}\right)^{2}\right]
$$

where, $T_{e}$ and $\Delta T$ refer to the equilibrium temperature and time dependent degree of subcooling at the PSN pressure, respectively. $\Delta T / T_{e}$ is a relative degree of subcooling. Eq. (2) above also involves a kinetic factor, $K_{J} \quad(\mathrm{~m}-3 \quad \mathrm{~s}-1)$, and a dimensionless thermodynamic parameter, b. The feasibility of applying Eq. (2) with a further explanation on use of parameters $K_{J}$ and $b$ has been studied elsewhere [15].

Based on Eq. (2), the average nucleation rate at the different values of $\gamma m$ examined, was calculated along the cooling process for the last 10 min prior to PSN (start of spontaneous growth), as shown in Fig. 2. In this figure the time elapsed before hydrate onset was negative since the onset point was defined as time zero for the process. For the analysis the kinetic factor $K_{J}$ and the thermodynamic parameter b in Eq. (2) were set to be $1.00 \mathrm{E}+21 \mathrm{~m}-3 \mathrm{~s}-1$ and 0.38 for cubic nuclei respectively. The value of $K_{J}$ was suggested by Kaschiev et al. [17] for systems with heterogeneous nucleation (HEN) as in this case.

As seen from the nucleation rates in Fig. 2, $\gamma m$ had no significant effect on the average nucleation rate and all numbers are close to $1 \times 10^{21}$ (differences less than $0.008 \%$ ). Kashchiev's model as described by Eq. (2) would give more or less a constant nucleation rate as indicated by its kinetic parameter $K_{J}(1.00 \mathrm{E}+21$ $\mathrm{m}-3 \mathrm{~s}-1)$ when degree of subcooling is within a small magnitude $\left(\Delta T<5{ }^{\circ} \mathrm{C}\right)$.

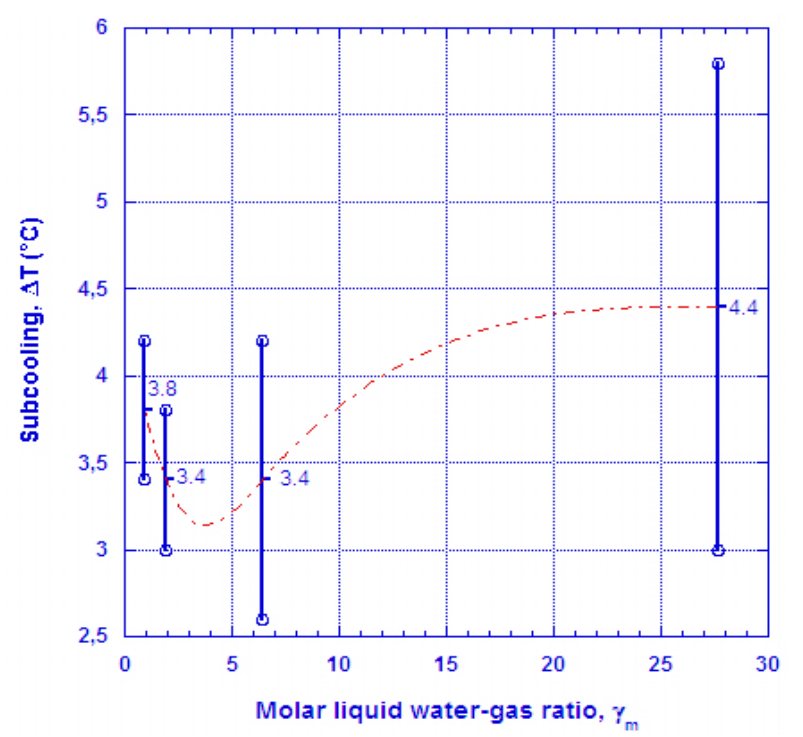

Fig. 1 Graph showing the degree of subcooling as function of molar liquid water-gas ratio. The stippled curve is based on cubic spline fit of the average $\Delta T$. 


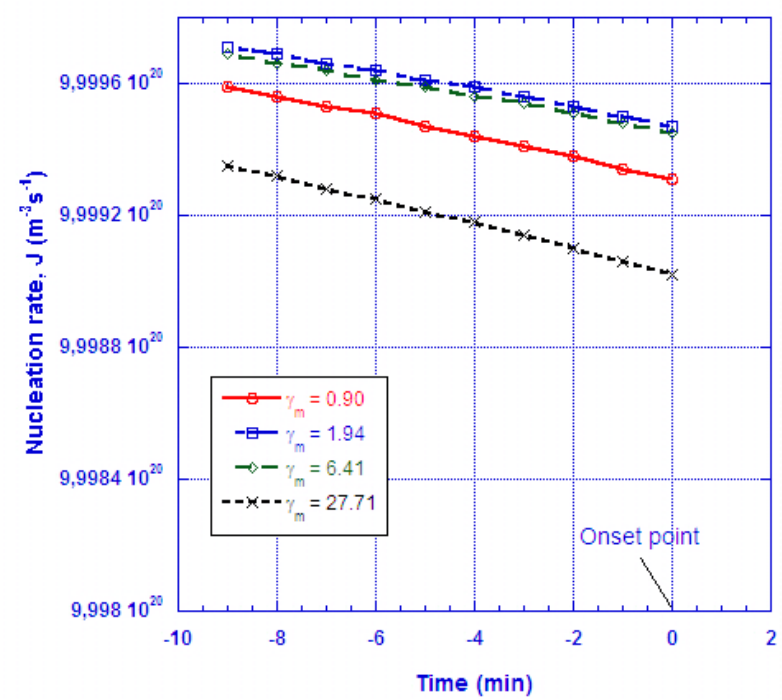

Fig. 2 Average nucleation rate, $\mathrm{J}\left(\mathrm{m}^{-3} \mathrm{~s}^{-1}\right)$ during the last 10 min prior to PSN.

As shown in Table 1 and Fig. 1, both the induction time and degree of subcooling at all water volumes and all values of $\gamma_{m}$ were of the same magnitude. However, the standard deviation was doubled when the water volume was increased to $50 \mathrm{~mL}$ as compared to $10 \mathrm{~mL}$ and $20 \mathrm{~mL}$. The standard deviation for the $100 \mathrm{~mL}$ water experiments further increased to 3.5 times as compared to the experiments with 10 and $20 \mathrm{~mL}$ water. This revealed a clear trend that increased molar liquid water-gas ratio $\left(\gamma_{m}\right)$ gave a more stochastic nucleation process. Since the average and SD were based on 10 experiments at each $\gamma_{m}$, the trend was assumed significant.

In more common heterogeneous nucleation (HEN), as in our work, nucleation rate $\mathrm{J}$ is normally controlled by impurities or surfaces present in the bulk liquid phase or equipment surfaces in contact with the bulk phase. An extra particle could offer extra surface to promote nucleation by reducing the threshold value of interfacial energy. Though HEN needs to conquer a higher $\Delta G$ barrier as compared to homogeneous nucleation $(\mathrm{HON})$, the critical size for realizing spontaneous crystal growth would be smaller [18]. A constant concentration of impurity particles in our DIW during all experiments has been assumed. When the total volume of the bulk liquid phase (and $\gamma_{m}$ ) increases, the space available for the continuous agglomeration and dissociation of methane hydrate nuclei would be increased and the occurrence of PSN to initiate spontaneous growth stage might then be more random. Dividing hydrate formation process into inter-related elementary reaction steps as proposed by Lekvam and Ruoff [19], the rate limiting step for nucleation could be the slow, uncatalyzed formation of hydrate from oligomeric precursor structures. Though rate constants for precursor formation and transformation into hydrates are not clear functions of $\gamma_{m}$, any change in the probability level for both precursors and initially formed hydrate crystals to trigger the autocatalytic and catastrophic hydrate growth may result in small response changes, as shown in Table 1 and Fig. 1.

\subsection{Hydrate Growth}

Growth behavior during the first $10 \mathrm{~min}$ after hydrate onset was analyzed and results are presented in Tables 2 and 3 and in Figs. 3-6. The real gas equation $\mathrm{PV}=\mathrm{znRT}$, a hydration number of 5.9 [20-21] and a compressibility factor $z$ of 0.830 were used to calculate the amount of gas present (in mol) or the amount of gas consumed per time unit (in $\mathrm{mol} / \mathrm{min}$ ) during the first 10 minutes after PSN. The compressibility factor $\mathrm{z}$ was obtained by use of the AGA8 program. The pressure drop over the first 10 minutes of the growth process was relatively moderate (less than 10 bar) for water experiments of all examined molar liquid water-gas ratios and effect of changes in compressibility factor could be neglected (1.5\% or less). This is assumed to be within a reasonable accuracy for comparisons made in the present work.

As some research groups have pointed out, an increase of degree of subcooling would lead to increasing hydrate growth rate [22-23]. To compare growth rates at the various values $\gamma_{m}$ examined, experiments with comparable $\Delta T$ values at PSN were therefore selected for calculation and comparisons. At 
$10 \mathrm{~mL}, 20 \mathrm{~mL}, 50 \mathrm{~mL}$ and $100 \mathrm{~mL}$ growth experiment selected, $\Delta T$ was $3.74{ }^{\circ} \mathrm{C}, 3.83{ }^{\circ} \mathrm{C}, 3.71{ }^{\circ} \mathrm{C}$ and $3.73{ }^{\circ} \mathrm{C}$, respectively at PSN with no dramatic changes during the following $10 \mathrm{~min}$ period of analysis. At these very close $\Delta T$ values it is assumed that potential effect of subcooling on the growth were minimized and thus could be neglected.

Growth results of examined water-gas ratios, $\gamma_{m}$, are given in Table 2.

Figs. 3 and 4 show time-dependent gas consumption (in mol) and gas consumption rate (in $\mathrm{mol} / \mathrm{min}$ ) at the different molar water-gas ratios applied, respectively. A pseudo-steady-state approximation was made, assuming that at any time the rate of gas consumed by growing hydrate equals the rate of gas consumed from the gas phase. For simplicity, the gas consumption rate as calculated by change in moles of gas with time ( $\mathrm{mol} / \mathrm{min})$ was equivalently taken as hydrate growth rate in this work.

Figs. 5 and 6 show the total gas intake (mol) and the initial and average growth rate ( $\mathrm{mol} / \mathrm{min})$ in columns, respectively.

A more detailed water-gas conversion factsheet within the first $10 \mathrm{~min}$ after hydrate onset is summarized in Table 3.

Fig. 7 shows the variation of real time molar liquid water-gas ratio $\left(\gamma_{m}\right)$ throughout the $10 \mathrm{~min}$ period of growth analysis after PSN.

From Table 3, it is seen that $\gamma_{m}$ is slightly decreasing for the 10 and $20 \mathrm{~mL}$ water experiments while $\gamma_{m}$ is slightly increasing for the 50 and $100 \mathrm{~mL}$ experiments over the $10 \mathrm{~min}$ period of analysis. All hydrate forming experiments remained at a fairly constant water-gas molar ratio over the period of analysis. The conditions were maintained as either water excess (100 mL DIW experiment) or gas excess (10 $\mathrm{mL}$ and $20 \mathrm{~mL}$ DIW experiment) or close to stoichiometric (50 mL DIW experiment) throughout the $10 \mathrm{~min}$ period of growth analysis. The relatively small variations in $\gamma_{m}$ over the period of analysis helped make a fair comparison of growth results. Similarly, the $\Delta T$ s at.

Table 2 Results of growth experiments with varying molar liquid water - gas ratio, $\gamma_{m}$, within the first 10 min after hydrate onset.

\begin{tabular}{cccc}
\hline Initial Molar liquid water-gas ratio $\left(\gamma_{\mathrm{m}}\right)$ & Total gas intake $(\mathrm{mol})$ & Initial growth rate $(\mathrm{mol} / \mathrm{min})$ & Average growth rate $(\mathrm{mol} / \mathrm{min})$ \\
\hline 0.90 & 0.022 & 0.0018 & 0.0022 \\
1.94 & 0.032 & 0.0030 & 0.0032 \\
6.41 & 0.033 & 0.0050 & 0.0033 \\
27.71 & 0.020 & 0.0015 & 0.0020 \\
\hline
\end{tabular}

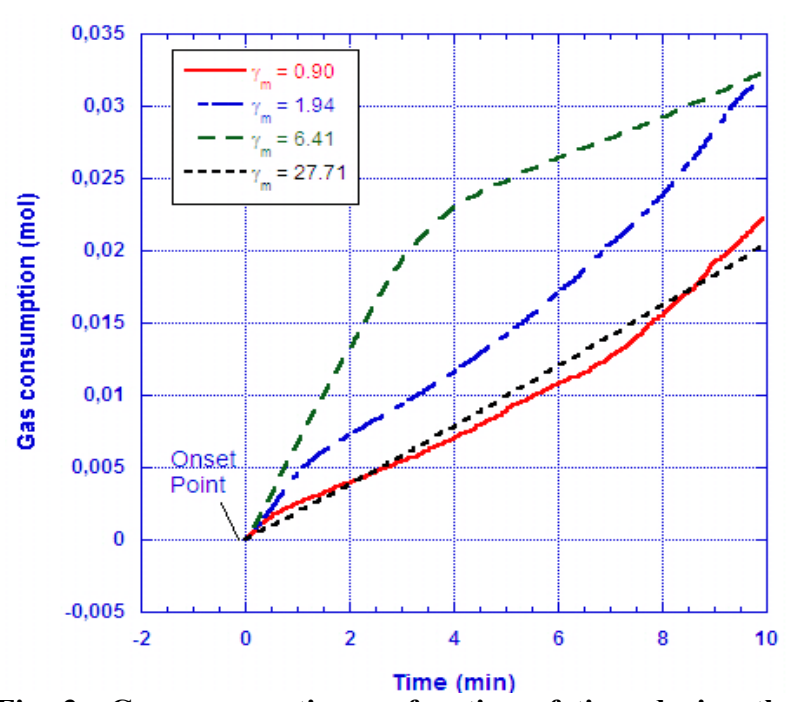

Fig. 3 Gas consumption as function of time during the first 10 min after PSN.

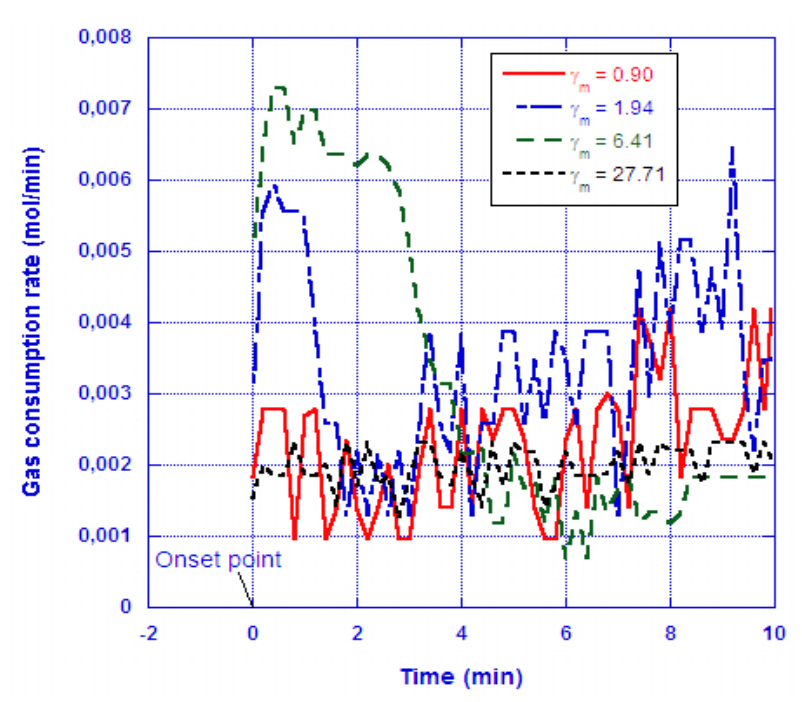

Fig. 4 Gas consumption rate as function of time during the first 10 min after PSN. 


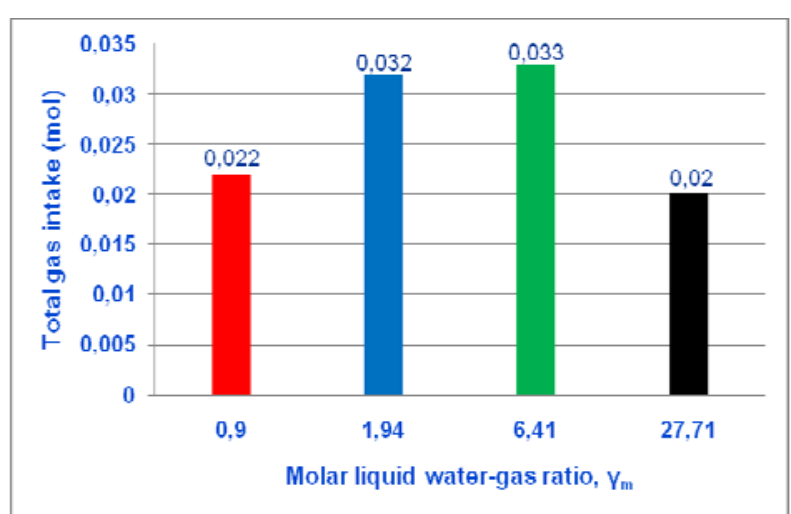

Fig. 5 Total gas intake at varying molar water-gas ratios during the first $10 \mathrm{~min}$ after PSN.

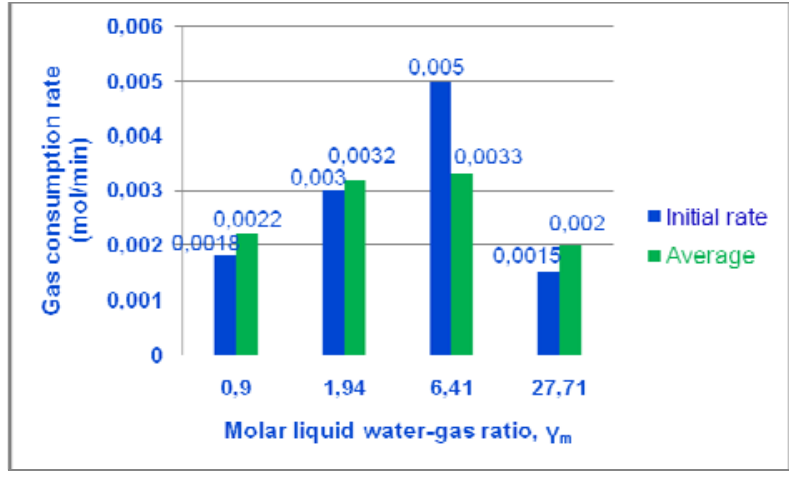

Fig. 6 Initial (blue) and average (green) gas consumption rate at varying water-gas ratios during the first $10 \mathrm{~min}$ after PSN.

Table 3 Water-gas conversion and hydrate formation factsheet.

\begin{tabular}{ccccc}
\hline Initial DIW $(\mathrm{mol})$ & Initial Methane (mol) & Initial $\gamma_{m}$ & Final $\gamma_{m}$ & Total sI hydrate formed (mol) \\
\hline 0.556 & 0.617 & 0.90 & 0.71 & 0.022 \\
1.111 & 0.572 & 1.94 & 1.71 & 0.032 \\
2.778 & 0.434 & 6.41 & 6.45 & 0.033 \\
5.556 & 0.200 & 27.71 & 30.18 & 0.020 \\
\hline
\end{tabular}

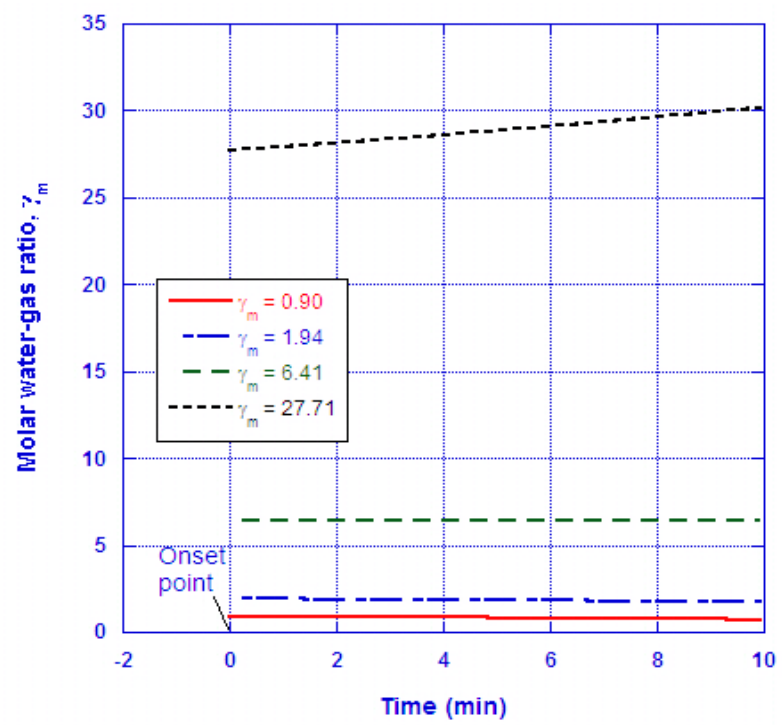

Fig. 7 Variation of molar liquid water-gas ratio with time during the first 10 min after PSN.

PSN in all growth experiments were of similar magnitude, as mentioned previously (from 3.71 to $\left.3.83^{\circ} \mathrm{C}\right)$.

From Tables 2 and 3, and Figs. 3-6, growth results of all examined molar liquid water-gas ratios could be divided into two groups:

Group 1: The most gas excess (10 mL DIW experiment, initial $\gamma m=0.90)$ and most water excess (100 mL DIW experiment, initial $\gamma m=27.71)$;
Group 2: Experiments with more moderate $\gamma_{m}$ values $\left(20 \mathrm{~mL}\right.$ DIW experiment, initial $\gamma_{m}=1.94$ and $50 \mathrm{~mL}$ DIW experiment, initial $\gamma_{m}=6.41$ ).

Compared to Group 1, Group 2 showed both larger total gas consumption and higher hydrate formation rate. The $50 \mathrm{~mL}$ DIW growth experiment where $\gamma_{m}$ was closest to theoretic hydration number of 5.9 to 6 , achieved highest total gas consumption and highest growth rate (both initial and average).

In Figs. 3 and 4, it can be seen that experiments in Group 1 show less gas consumption and lower growth rate. In addition, the growth rate for the Group 1 experiments showed less fluctuation over the period of analysis as compared to experiments in Group 2. Previous studies have reported that the overall hydrate growth rate could be a linearly, decreasing function of time, given that mass transport is smooth for hydrate formation [24]. In this case, it is apparently true for the Group 1 condition. A very "unbalanced" molar liquid water-gas ratio could possibly retard the water and methane gas transport to reaction sites and thus force the system to behave in a smoother manner. Efficiency of reducing heat transfer resistance could be another factor affecting the hydrate growth 
behavior [16, 21]. However, in this wok, with sufficient continuous cooling and stirring, it is assumed that heat dissipation had already been optimized to reduce/minimize all heat transfer resistance that could retard methane hydrate growth.

Last but not least, the total methane gas consumption by mol percent was $3.60 \%, 5.59 \%$, $7.45 \%$ and $10.14 \%$ for the $10,20,50$ and $100 \mathrm{~mL}$ water experiments respectively. Similarly, the total liquid water consumption was $23.6 \%, 17.0 \%, 6.87 \%$ and $2.16 \%$ for the $10,20,50$ and $100 \mathrm{~mL}$ water experiments respectively (dissolved methane gas in the liquid phase was neglected in this analysis due to its low solubility in water). Even an optimized $\gamma_{m}$ could be found to have maximum water and gas conversion into hydrates, and complete conversion is not obtainable. A possible reason for that is part of residual free water molecules could always be wedged between formed hydrate crystals [25].

\section{Conclusions}

Experimental study on effect of molar liquid water-gas ratio $\left(\gamma_{m}\right)$ on methane hydrate nucleation and growth has been performed in a lab scale isochoric cell. Results have shown that an increase of $\gamma_{m}$ from 0.90 to 27.71 covering both gas-excess and water-excess region had no effect on average nucleation rate, when degree of subcooling was kept in a relatively small range $\left(\left(\Delta T<5^{\circ} \mathrm{C}\right)\right.$. Nevertheless, increasing $\gamma_{m}$ made the nucleation process more stochastic. Moderate $\gamma_{m}$ values closer to a theoretical hydration number of 5.9 to 6 gave larger total gas consumption and higher hydrate formation rate as compared to the extremities of highly gas excess or water excess. A complete water or gas conversion into solid hydrates is commonly not obtained, partly because there always would be free water molecules wedged and captured between formed hydrate crystals that prevent exposure to and contact with the hydrate forming gas.

\section{Acknowledgments}

The authors thank the Ministry of Education and Research of Norway (Kunnskapsdepartementet) and the University of Stavanger for the financial support of this work.

\section{References}

[1] E.D. Sloan, C.A. Koh, Clathrate Hydrates of Natural Gases, 3rd ed., CRC Press/Tayler \& Francis: Boca Raton, FL, 2008, pp. 113-187.

[2] A.K. Sum, C.A. Koh, E.D. Sloan, Clathrate hydrates: From laboratory science to engineering practice, Ind. Eng. Chem. Res. 48 (2009) 7457-7465.

[3] D. Kashchiev, A. Firoozabadi, Nucleation of gas Hydrates, Journal of Crystal Growth 243 (2002) 476-489.

[4] D. Kashchiev, A. Firoozabadi, Induction time in crystallization of gas hydrates, Journal of Crystal Growth 250 (2003) 499-515.

[5] JS.. Parent, P.R. Bishnoi, Investigations into the nucleation behavior of methane gas hydrates, Chem. Eng. Comm. 144 (1996) 51-64.

[6] P. Englezos, N. Kalogerakis, P.D. Dholabhai, P.R. Bishnoi, Kinetics of formation of methane and ethane gas hydrates, Chemical Engineering Science 42 (1987) 2647-2658.

[7] A. Vysniauskas, P.R. Bishnoi, A kinetic study of methane hydrate formation, Chemical Engineering Science 38 (1983) 1061-1072.

[8] A. Svandal, B. Kvamme, L. Granasy, T. Pusztai, T. Buanes, J. Hove, The phase-field theory applied to $\mathrm{CO}_{2}$ and $\mathrm{CH}_{4}$ hydrate, Journal of Crystal Growth 287 (2006) 486-490.

[9] Jr.Cp. Ribeiro, P.L.C. Lage, Modelling of hydrate formation kinetics: State-of-the-art and future directions, Chemical Engineering Science 63 (2008) 2007-2034.

[10] C. Moon, R.W. Hawtin, P.M. Rodger, Direct molecular simulations of hydrate nucleation, in: Proceedings of the 5th International Conference on Gas Hydrates, Trondheim, Norway, 2005.

[11] S. Toschev, A. Milchev, S. Stoyanov, On some probabilistic aspects of the nucleation process, Journal of Crystal Growth 13-14 (1972) 123-127.

[12] P. Skovborg, H.J. Ng, P. Rasmussen, U. Mohn, Measurement of induction times for the formation of methane and ethane gas hydrates, Chemical Engineering Science 48 (1993) 445-453.

[13] W. Ke, T.M. Svartaas, Effects of stirring and cooling on methane hydrate formation in a high-pressure isochoric cell, in: Proceedings of the 7th International Conference on Gas Hydrates, Edinburgh, Scotland, United Kingdom, 
2011.

[14] T.M. Svartaas, F.H. Fadnes, Methane hydrate equilibrium data for the methane-water-methanol system up to 500 bara, in: Proceedings of the 2nd International Offshore and Polar Engineering Conference, San Francisco, USA, 1992.

[15] W. Ke, T.M. Svartaas, H.K. Abay, Effects of low concentration methanol, PVP and PVCap on Structure-I methane hydrate formation, Journal of Energy and Power Engineering 7 (2013) 432-439.

[16] J.P. Osegovic, S.R. Tatro, S.A. Holman, A.L. Ames, M.D. Max, A growth kinetics of ethane hydrate from a seawater solution at an ethane gas interface, Journal of Petroleum Science and Engineering 56 (2007) 42-46.

[17] D. Kashchiev, A. Borissova, R.B. Hammond, K.J. Roberts, Effect of cooling rate on the critical undercooling for crystallization, Journal of Crystal Growth 312 (2010) 698-704.

[18] S. Takeya, A. Hori, T. Hondoh, T. Uchida, Freezing-memory effect of water on nucleation of $\mathrm{CO}_{2}$ hydrate crystals, J. Phys. Chem. B 104 (2000) 4164-4168.

[19] K. Lekvam, P. Ruoff, A reaction kinetic mechanism for methane hydrate formation in liquid water, J. Am. Chem. Soc. 115 (1993) 8565-8569.

[20] H.K. Abay, T.M. Svartaas, Effect of ultralow concentration of methanol on methane hydrate formation, Energy Fuels 24 (2) (2010) 752-757.

[21] G.K. Anderson, Enthalpy of dissociation and hydration number of methane hydrate from the clapeyron equation, J. Chem. Thermodynamics 36 (2004) 1119-1127.

[22] E.M. Freer, M.S. Selim, E.D. Sloan, Methane hydrate film growth kinetics, Fluid Phase Equilibria 185 (2001) $65-75$.

[23] T. Uchida, I.Y. Ikeda, S. Takeya, T. Ebinuma, J. Nagao, H. Narita, $\mathrm{CO}_{2}$ hydrate film formation at the boundary between $\mathrm{CO}_{2}$ and water: Effects of temperature, pressure and additives on the formation rate, Journal of Crystal Growth 237-239 (2002) 383-387.

[24] P. Skovborg, P. Rasmussen, A mass transport limited model for the growth of methane and ethane gas hydrates, Chemical Engineering Science 49 (1994) 1131-1143.

[25] E. Berecz, M. Balla-Achs, Studies in inorganic chemistry: 4. Gas hydrates, Elsevier Science Publishers, United Kingdom (1984) 194-204. 